\title{
A FRAMEWORK FOR MEASURING HAPPINESS IN ONLINE SOCIAL NETWORKS
}

\author{
Amy Y. Chou, Illinois State University, aychou@ilstu.edu \\ Billy B. L. Lim, Illinois State University,bllim@ilstu.edu
}

\begin{abstract}
Research on happiness has been conducted for many decades with various interesting results reported by different groups of researchers. While there is a plethora of research efforts on happiness in general, there is little work being done to study the effects of online social networks on happiness. This is mainly due to the relative (in)maturity of online social networking as it has only been around for the last few years. This research attempts to answer if the offline social network phenomenon can be carried towards its online social network counterpart such as Facebook and MySpace, both of which have millions of active users. This paper describes the first phase of the research, where a framework for modeling happiness from a more comprehensive perspective is presented. A multi-dimensional happiness measure is developed based on Ryff's well-being theory [8] and its reliability and validity are discussed in this paper.
\end{abstract}

Keywords: Social Network, Happiness, Well-being, Measurement

\section{INTRODUCTION}

For decades, medical doctors, economists, psychologists, and sociologists, among others, have been studying the topic of happiness for obvious reasons - (most) people are in pursuit of happiness! Many interesting results have been reported on various perspectives over the years. Psychology researchers suggest that happiness is a function of multi-dimensional factors [8,9]. Research results also show that people who are happy and satisfied with their lives might be healthier down the road (in as little as 3 years) [10]. Some researchers suggest that the relationship between wealth and happiness is a complicated one [11].

More recently, a study just published in the British Medical Journal reports on the effort to evaluate whether happiness can spread from person to person and whether clusters of happiness form within social networks [5]. This fascinating, 20-year longitudinal study received tremendous attention in the literature and also the public air waves as it was the lead story in NBC, the major TV networks and other major Internet outlets [6]. This study is the first to state that people who are surrounded by many happy people and those who are central in the network are more likely to become happy in the future. Here, centrality refers to the notion of a person/node that is in the middle of multiple connections in a social network.

This important study provides further justification that happiness, like health, should be regarded as a collective phenomenon. One's wellness, whether it is happiness or health related, is indeed a function of one's surroundings and not just personal experiences.

As a follow-up to the aforementioned study, Fowler et al. investigated the effect of online social networking on happiness. Online social networking is a burgeoning phenomenon that has taken the Web by storm. As part of the broader umbrella of Web 2.0, social networks such as MySpace and Facebook have enjoyed exponential growth in recent years. A recent report states that about 125 million people visited MySpace worldwide in December, '09 versus 222 million people for Facebook [1]. This means 22\% of the total Internet audience went to Facebook in December, a phenomenal growth for social networking.

With this skyrocketing growth, no wonder so many researchers are studying online social networking for different purposes. In the case of Fowler et al., their follow-up study [4] examines college students and their interconnected friends in Facebook. The methodology used is that they examined the students' online profiles and studied their photographs. Students who appeared in photographs with their friends are tagged as "picture friends" (i.e., close ones), which are distinguished from other, not as close friends. Also, students who smile in their profiles are considered happy. (Note: The authors concede that this approach is not equivalent to their offline study and we agree-most people smile in photos regardless of true happiness). With these factors, they performed an analysis of the happiness contagion on Facebook social network, representing an approximate analogue of their offline social network study. 
The result of the Facebook study is that they observed similar clustering of happy and unhappy persons, i.e., result indicating large-scale structure of smiling in the online network. Furthermore, people who smile tend to have more close friends and those who do not tend to be in the peripherals of the network. Lastly, those who smile are measurably more central to the network compared to those who do not smile. Thus, they conclude that, online or offline, "when you smile, the world smiles with you!"

Similar to the above, this multi-phase research proposes to study the effects of happiness on online social networks and asks the research question: "Is happiness contagious in online social networks?" Namely, it intends to examine if a person with online social network friends who are happy is also likely to be happy or not. Unlike the above follow-up study, however, this research will not rely on smile-on-aphotograph to denote happiness as they are not equivalent, as conceded by the study authors. Instead, online social networks friends are surveyed on a multi-dimensional scale that determines happiness.

Given the popularity and ubiquity of social networking in the online world, this research is timely and relevant as many people are relying on the online outlets for their social lives, sometimes even exclusively. An important research contribution of this study is that it answers if some of the comprehensive happiness research results by Fowler et al. can be claimed in the online world. As mentioned earlier, online social networking is a burgeoning field in information technology and a study of happiness on the field is an important contribution to information technology and overall happiness research in general. The results of this study can contribute to the literature on online social network research and further understand the social aspects of computing that information technology can indeed increase the well-being of end users.

This paper discusses the result of the first phase of the multi-phase research. It presents a framework that allows for the modeling of happiness in online social networks. Using the Ryff's well-being theory [8] as the base, a more comprehensive measurement for happiness is presented. Instead of using a single dimensional measure, which is used in Fowler and Christakis's research, a multi-dimensional happiness measure is developed. The framework and the validity of the measurements are discussed next.

\section{METHODOLOGY}

\section{Scale Development}

The happiness research conducted by Fowler and Christakis [5] used a subset of Center for Epidemiological Studies depression scale (CES-D) to measure happiness. Subjects of their study were asked how often they experienced certain feelings during the previous week in the following four items: "I felt hopeful about the future," "I was happy," "I enjoy my life," and "I felt that I was just as good as other people." A perfect score on all four questions indicates that an individual is very happy. Therefore, in Fowler and Christakis [5] study, "happiness" was treated as a single dimensional measure.

Psychology literatures [8, 9] have suggested that happiness is not a single dimensional concept. Instead, there are multiple factors that contribute to the feeling of happiness. Happiness as a matter of fact involves various aspects of positive psychological functioning, such as self-actualization, individuation, maturity, and fulfillment of life.

This study takes a more complex view of happiness. Instead of using a single factor measure, we develop a multidimensional measure of happiness based on Ryff's [8] six dimensions of psychological wellbeing theory. "Self-acceptance" refers to the extent in which one holds positive image and attitude toward oneself. "Positive relation with others" refers to the extent in which one forms warm, satisfying, trusting relationship with others. "Autonomy" refers to the extent in which one is self-determining, independence, and being able to resist social pressures and regulate oneself from within. "Environmental mastery" refers to the extent in which one feels competent in choosing or creating contexts suitable to personal needs and values. "Purpose of life" refers to the extent in which one has goal in life and a sense of direction. "Personal growth" refers to the extent in which one has a feeling of continued development.

The six dimensions of well-being can be measured by positive and negative feeling of oneself. In this paper we will focus on the measure of one's positive emotion in each dimension. Based on Ryff's theory [8], 24 items were developed to measure one's wellbeing. The items of each scale are list in the table 1 . 
Table 1: Measurement Items of Multidimensional Well-being

\begin{tabular}{|c|c|}
\hline Label & Item Description \\
\hline \multicolumn{2}{|l|}{$\begin{array}{l}\text { Self } \\
\text { Acceptance }\end{array}$} \\
\hline SA1 & I feel good about myself. \\
\hline SA2 & I have a lot of good qualities. \\
\hline SA3 & I have some weaknesses. \\
\hline \multicolumn{2}{|l|}{$\begin{array}{l}\text { Relationship } \\
\text { with Others }\end{array}$} \\
\hline REL1 & I have many trusting friends. \\
\hline REL2 & $\begin{array}{l}\text { I have satisfying relationships with } \\
\text { my friends. }\end{array}$ \\
\hline REL3 & I care about my friends. \\
\hline REL4 & $\begin{array}{l}\text { I often share my feeling with my } \\
\text { friends. }\end{array}$ \\
\hline \multicolumn{2}{|l|}{ Autonomy } \\
\hline AUTO1 & I am a self-determined person. \\
\hline AUTO2 & $\begin{array}{l}\text { I don't let social pressure affect my } \\
\text { decision. }\end{array}$ \\
\hline AUTO3 & I act upon what I believe. \\
\hline AUTO4 & $\begin{array}{l}\text { I evaluate myself based on my own } \\
\text { standards. }\end{array}$ \\
\hline \multicolumn{2}{|l|}{$\begin{array}{l}\text { Environment } \\
\text { al Mastery }\end{array}$} \\
\hline ENVM1 & $\begin{array}{l}\text { I am competent to manage my } \\
\text { regular routines. }\end{array}$ \\
\hline ENVM2 & $\begin{array}{l}\text { I am good at juggling different } \\
\text { activities. }\end{array}$ \\
\hline ENVM3 & $\begin{array}{l}\text { I will take the surrounding } \\
\text { opportunity whenever it presents. }\end{array}$ \\
\hline ENVM4 & $\begin{array}{l}\text { I believe that I can overcome } \\
\text { hardship if it ever occurs. }\end{array}$ \\
\hline \multicolumn{2}{|l|}{$\begin{array}{l}\text { Purpose of } \\
\text { Life }\end{array}$} \\
\hline PURP1 & I know what are meaningful to me. \\
\hline PURP2 & $\begin{array}{l}\text { I know the important goals I want to } \\
\text { achieve in my life. }\end{array}$ \\
\hline PURP3 & $\begin{array}{l}\text { I know what make me passionate } \\
\text { about my future. }\end{array}$ \\
\hline PURP4 & $\begin{array}{l}\text { I know what are most important to } \\
\text { me in my life. }\end{array}$ \\
\hline \multicolumn{2}{|l|}{$\begin{array}{l}\text { Personal } \\
\text { Growth }\end{array}$} \\
\hline GROW1 & $\begin{array}{l}\text { I continue learning new things every } \\
\text { day. }\end{array}$ \\
\hline GROW2 & $\begin{array}{l}\text { I can see myself growing in many } \\
\text { ways. }\end{array}$ \\
\hline GROW3 & I am open to a new experience. \\
\hline GROW4 & I like to improve myself continually. \\
\hline GROW5 & $\begin{array}{l}\text { I know I have potential to learn } \\
\text { through my whole life. }\end{array}$ \\
\hline
\end{tabular}

Data Collection
College student is one of the largest user groups in online social networking. We decide to use college students, who use online social network websites such as Facebook or MySpace to contact and exchange information with their friends, as our subjects in this pilot study. An online survey was distributed via email to six classes of college students, who major in information technology in a Midwestern university. Sixty six useful responses were returned.

\section{Reliability and Factorial Structure}

According to the sampling domain model, all the items in the same measure are drawn from the domain of a single construct. Thus the responses to those items in the same measure should be highly inter-correlated [2]. Cronbach's alpha (1951) is assessed for each scale. To improve alpha coefficient, items with corrected item-to-total correlation (CITC) lower than 0.5 are removed. The alpha coefficient and CITC of each item are displayed in the Table 2. Alpha value of each scale is above 0.7, which shows that each scale has sufficient reliability [7].

Table 2: Alpha Coefficients and CITC

\begin{tabular}{|c|c|c|}
\hline Label & CITC & Item Description \\
\hline $\begin{array}{l}\text { Self } \\
\text { Acceptance }\end{array}$ & & $($ Alpha $=.811)$ \\
\hline SA1 & .702 & I feel good about myself. \\
\hline SA2 & .702 & I have a lot of good qualities. \\
\hline $\begin{array}{l}\text { Relationship } \\
\text { with Others }\end{array}$ & & $($ Alpha $=0.748)$ \\
\hline REL1 & .670 & I have many trusting friends. \\
\hline REL2 & .716 & $\begin{array}{l}\text { I have satisfying relationships } \\
\text { with my friends. }\end{array}$ \\
\hline REL3 & .507 & I care about my friends. \\
\hline Autonomy & & $($ Alpha $=0.751)$ \\
\hline AUTO1 & .497 & $\begin{array}{l}\text { I am a self-determined } \\
\text { person. }\end{array}$ \\
\hline AUTO2 & .642 & $\begin{array}{l}\text { I don't let social pressure } \\
\text { affect my decision. }\end{array}$ \\
\hline AUTO3 & .654 & I act upon what I believe. \\
\hline AUTO4 & .643 & $\begin{array}{l}\text { I evaluate myself based on } \\
\text { my own standards. }\end{array}$ \\
\hline $\begin{array}{l}\text { Environmenta } \\
\text { l Mastery }\end{array}$ & & $($ Alpha $=0.839)$ \\
\hline ENVM1 & .803 & $\begin{array}{l}\text { I am competent to manage } \\
\text { my regular routines. }\end{array}$ \\
\hline ENVM2 & .676 & $\begin{array}{l}\text { I am good at juggling } \\
\text { different activities. }\end{array}$ \\
\hline ENVM4 & .640 & $\begin{array}{l}\text { I believe that I can overcome } \\
\text { hardship if it ever occurs. }\end{array}$ \\
\hline Purpose of & & $($ Alpha $=0.914)$ \\
\hline
\end{tabular}




\begin{tabular}{|l|l|l|}
\hline Life & & \\
\hline PURP2 & .823 & $\begin{array}{l}\text { I know the important goals I } \\
\text { want to achieve in my life. }\end{array}$ \\
\hline PURP3 & .827 & $\begin{array}{l}\text { I know what make me } \\
\text { passionate about my future. }\end{array}$ \\
\hline PURP4 & .829 & $\begin{array}{l}\text { I know what are most } \\
\text { important to me in my life. }\end{array}$ \\
\hline $\begin{array}{l}\text { Personal } \\
\text { Growth }\end{array}$ & .777 & $\begin{array}{l}\text { I continue learning new } \\
\text { things every day. }\end{array}$ \\
\hline GROW1 & .764 & $\begin{array}{l}\text { I can see myself growing in } \\
\text { many ways. }\end{array}$ \\
\hline GROW2 & .776 & $\begin{array}{l}\text { I am open to a new } \\
\text { experience. }\end{array}$ \\
\hline GROW3 & .844 & $\begin{array}{l}\text { I like to improve myself } \\
\text { continually. }\end{array}$ \\
\hline GROW4 & &
\end{tabular}

The purified items are then analyzed with factor analysis to examine the underlying factorial structure. The criterion to retain the factors in this step of data analysis is based on Kaiser's rule. The rule states that only those factors whose eigenvalues are greater than 1 should be retained. A varimax rotation is applied in factor analysis to maximize the sum of the variances of the squared loadings. The items cross loading into more than one factor and with the loading factor greater than 0.4 are eliminated from further process. Eventually, four factors were extracted from remaining 11 items. These four factors explain $78.89 \%$ of overall variance. Table 3 exhibits the items in each factor and its factor loading.

Table 3: Rotated Component Matrix ${ }^{\mathrm{a}}$

\begin{tabular}{|l|r|r|r|r|}
\hline \multirow{2}{*}{} & \multicolumn{4}{|c|}{ Component } \\
\cline { 2 - 5 } & 1 & \multicolumn{1}{c|}{2} & \multicolumn{1}{c|}{3} & \multicolumn{1}{c|}{4} \\
\hline SA1 & & & .841 & \\
SA2 & & & .906 & \\
REL1 & & .836 & & \\
REL2 & & .836 & & \\
REL3 & & .773 & & \\
AUTO3 & & & & .908 \\
AUTO4 & & & & .759 \\
GROW1 & .803 & & & \\
GROW2 & .830 & & & \\
GROW3 & .884 & & & \\
GROW4 & .869 & & & \\
\hline
\end{tabular}

Extraction Method: Principal Component Analysis.

Rotation Method: Varimax with Kaiser Normalization.

a. Rotation converged in 5 iterations.
According to Ryff's [8] well-being theory, there are six dimensions of well-being. However, from the results of the factor analysis of our pilot study we only discover four underlying factors, which are selfacceptance, positive relation with others, autonomy, and personal growth. The items that measure environmental mastery and purpose of life tend to covary with the items in other dimensions. Therefore those items were deleted, since they could not form an independent factor.

\section{DATA ANALYSIS AND DISCUSSIONS}

To further validate the four dimensional measurements of well-being, we further examine the relationship between the multidimensional well-being measurement model and online social network utilization variables. We added the individual item scores in each dimension (factor) to form a score for each factor. A total score of four factors represents the well-being score of each respondent. A bivariate correlation analysis is performed to test the following hypothesis:

H1: Online social network utilization is positively related to individual well-being (happiness).

Among the sixty six responses we collected, 63 respondents use Facebook, 6 respondents use Twitter, 6 respondents use MySpace, and 5 respondents use LinkedIn (see Figure 1). Most of us have the impression that college students spend a lot of time on online social network. Our data suggest the opposite. Since the size of our sample is fairly small, we do not intend to generalize our findings to the general population. According the data we collected, most respondents $(71.2 \%)$ spend 10 or less hours on the online social network (see Figure 2). Asking the respondents how often they update their status in social network sites, $62(94 \%)$ of respondents reported that they updated 0-2 times a day (see Figure 3 ). Asking the respondents how often they chat with their friends, $70 \%$ of respondents reported 0-2 time a day (see Figure 4). The profile of our respondents shows that college students are not as online social network active as we expected them to be. 
Figure 1: Type of Social Network Used

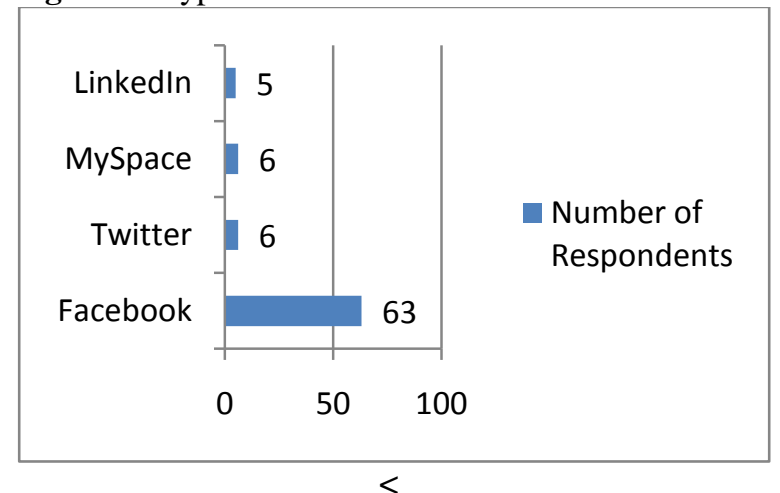

Figure 2: How many hours each week do you spend on online social networking?

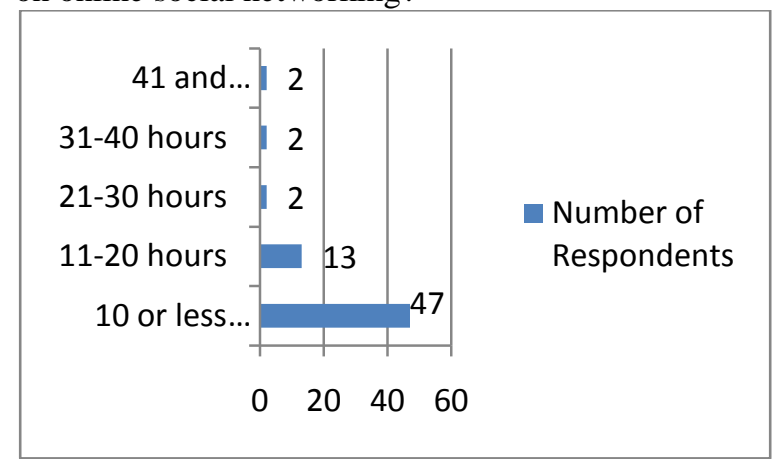

Figure 3: How often do you update your 'status' in social networking sites?

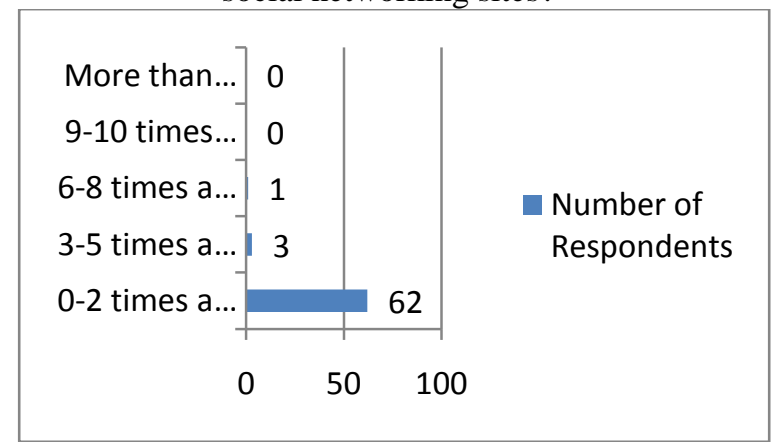

Figure 4: How often do you chat with your friends in social networking sites?

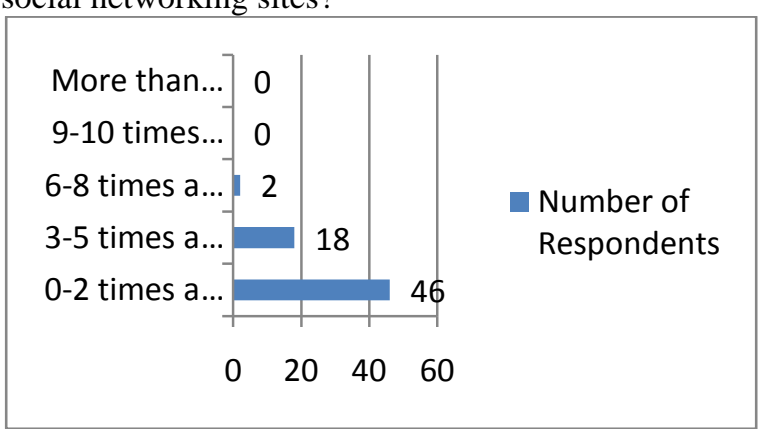

Volume XI, No. 1, 2010
After performed the correlation analysis between the pair of each well-being factor and three network utilization variables, the results show that none of the pair has significant relationship (see Table 4). These results suggest that there is no or little correlation between online network use and individual wellbeing. It seems that using online social network tools alone cannot improve one's well-being. However, online social network tools do provide conveniences and advantages to contact one's friends especially friends at distant locations. Our research interest is to find out whether the wellbeing of one's online friends is related one's wellbeing. In our next phase of research, we will use well-being measurement model developed in this study to measure wellbeing of one's online friends.

Table 4: Correlation between Network Use and Well-being

\begin{tabular}{|l|l|l|l|}
\hline & $\begin{array}{l}\text { Hours } \\
\text { Spent }\end{array}$ & $\begin{array}{l}\text { Frequency } \\
\text { of } \\
\text { Updating } \\
\text { Status }\end{array}$ & $\begin{array}{l}\text { Frequency } \\
\text { of Chat }\end{array}$ \\
\hline $\begin{array}{l}\text { Self } \\
\text { Acceptance }\end{array}$ & 0.080 & 0.073 & 0.099 \\
\hline $\begin{array}{l}\text { Positive } \\
\text { Relation } \\
\text { with Others }\end{array}$ & -0.087 & 0.083 & -0.182 \\
\hline Autonomy & -0.005 & 0.019 & -0.084 \\
\hline Self Growth & 0.068 & -0.018 & -0.127 \\
\hline $\begin{array}{l}\text { Overall } \\
\text { Well-being }\end{array}$ & 0.022 & 0.048 & -0.123 \\
\hline
\end{tabular}

\section{CONCLUSIONS AND FUTURE WORK}

The burgeoning field of online social networking has taken the world by storm in recent years. Given the ubiquity of the platform, it is important to research and understand the social aspects of computing on the well-being of the end users for the platform, including the topic of happiness and its contagion. This paper discusses the result of the first phase of a multi-phase research to answer if some of the offline comprehensive happiness research results by Fowler et al. can be claimed in the online world.

The paper presents a framework that allows for the modeling of happiness in online social networks. Based on Ryff's well-being theory (1989), a more comprehensive measurement for happiness is presented in this paper. Unlike Fowler and Christakis's research, which uses a single dimensional measure, this research uses a multidimensional happiness measure consisting of selfacceptance, positive relation with others, autonomy, 
personal growth, environmental mastery, and purpose of life. Factor analysis of the pilot study of this research discovers that of the above six, only the first four form the underlying, independent factors. The last two dimensions, i.e., environmental mastery and purpose of life, tend to co-vary with the items in other dimensions. The resulting model for measuring happiness, thus, consists of only self-acceptance, positive relation with others, autonomy, and personal growth, collectively forming the happiness index.

For the next phase of the research, the measurement model of well-being will be used to measure the level of happiness of the online friends of online social network users. The Participants and their online friends will be surveyed using the happiness framework proposed in this study. Our next phase of research is to test if a focal individual's happiness is influenced by his/her online friends' happiness. Various hypotheses that test the aforementioned 4 underlying factors as well as the overall happiness index will be developed. Structural equation modeling will be used to test the proposed hypotheses.

\section{REFERENCES}

1. Arrington, M. (2009), Facebook Now Nearly Twice The Size Of MySpace Worldwide. Retrieved January 222009 from http://www.techcrunch.com/2009/01/22/faceboo k-now-nearly-twice-the-size-of-myspaceworldwide/

2. Churchill, G. A. (1979). A Paradigm for Developing Better Measures of Marketing Constructs. Journal of Marketing Research, 16(1), 64-73.

3. Cronbach, L. J. (1951). Coefficient Alpha and the Internal Structure of Tests. Psychometrika, $16,297-334$.
4. Fowler, J. H. \& Christakis N. A. (2008). Edge: The Third Culture. Retrieved January 1, 2009 from http://server1.edge.org/3rd_culture/christakis_fo wler08/christakis_fowler08_index.html

5. Fowler J. H., \& Christakis N. A. (2008, December 4). Dynamic Spread of Happiness in a Large Social Network: Longitudinal Analysis Over 20 Years in the Farmingham Heart Study. British Medical Journal, Retrieved January 152009 from http://www.bmj.com/cgi/content/full/337/dec04_2/a23 $\underline{38}$

6. NBC Nightly News broadcast (2008), Retrieved January 1, 2009 from http://www.youtube.com/watch?v=mrKn0Q6tG $\underline{\mathrm{RW}}$

7. Nunnally, J. C. (1978). Psychometric Theory, McGraw-Hill, New York.

8. Ryff, C. D. (1989). Happiness Is Everything, or Is It? Explorations on the Meaning of Psychological Well-Being. Journal of Personality and Social Psychology, 57(6), 10691081.

9. Ryff, C. D., \& Keyes, L. M. (1995). The Structure of Psychological Well-Being Revisited. Journal of Personality and Social Psychology, 69(4), 719-727.

10. Siahpush, M, Spittal M, \& Singh G. K. (2008) Happiness and life satisfaction prospectively predict self-rated health, physical health, and the presence of limiting, long-term health conditions. American Journal Health Promotion, 23(1), 18-26.

11. Stevenson, B., \& Wolfers, J. (2008). Economic Growth and Subjective Well-Being: Reassessing the Easterlin Paradox. Brookings Papers on Economic Activity, 1, 1-87. 